\title{
Challenges and Strategies in Translating Chinese and English Prepositions into Standard Shona
}

\author{
Herbert Mushangwe \\ University of Zimbabwe, Harare
}

The present study focuses on the challenges and strategies in translating Chinese or English prepositions into Shona. These two languages were chosen mainly because Chinese is becoming one of the most influential foreign languages in Zimbabwe while, English is also one of the widely spoken foreign languages in many countries. As already observed in some previous research, English and Chinese prepositions are captured in Shona phrases as morphemes. Words are the smallest elements that may be uttered in isolation with semantic or pragmatic content. This differs from morphemes that are defined as smallest units of meaning, which cannot necessarily stand on their own. Research shows that Chinese and English prepositions do not have direct equivalent prepositions in Shona. We observed that Shona employs substitutes for Chinese and English prepositions, making translation of prepositions from other languages into Shona challenging.

Keywords: Prepositions; Shona; cross language comparison; Chinese and English, translation 